\title{
Frustrated Lewis pairs: Design and reactivity
}

\author{
SANJOY MUKHERJEE and PAKKIRISAMY THILAGAR* \\ Department of Inorganic and Physical Chemistry, Indian Institute of Science, Bangalore 560 012, India \\ e-mail: thilagar@ipc.iisc.ernet.in
}

MS received 7 October 2014; accepted 6 November 2014

\begin{abstract}
The interaction of a Lewis acid with a Lewis base results in the formation of a Lewis acid-base adduct. Understanding Lewis acids and bases is central to conceptualizing chemical interactions and constitutes a major portion of metal-ligand chemistry. Sterically encumbered/constrained Lewis pairs cannot form acidbase adducts, but such 'Frustrated Lewis Pairs' (FLPs), with their unquenched electronic demands can be elegantly used to simultaneously react with a third species, resulting in unusual reactivity of small molecules. Such unusual reactions, explored only in the last few years, have found several applications, e.g., heterolytic splitting of $\mathrm{H}_{2}$, activation of small molecules $\left(\mathrm{CO}_{2}, \mathrm{~N}_{2} \mathrm{O}\right.$, etc.). FLPs have opened new opportunities in synthetic chemistry, covering organic, main group as well as transition metal chemistry. The design strategies adopted for FLP systems and their unique reactivity are discussed here.
\end{abstract}

Keywords. Lewis acids; lewis bases; frustrated lewis pairs; catalysis; small-molecule activation; boranes; phosphines.

\section{Introduction}

\subsection{Lewis acid base chemistry}

The vast discipline of chemistry with its endless possible combinations requires systematic classification of materials into families of species for a better understanding of the subject. Accordingly, the classification of compounds into 'acids' and 'bases' have a profound effect on modern chemistry. ${ }^{1}$ Although, as chemists, we intuitively understand their meanings well enough, it is difficult to state their precise definitions in a single sentence.

In 1923, Gilbert N Lewis classified compounds as Lewis acids and bases according to their ability to accept or donate electron pairs. ${ }^{2}$ Lewis bases, with their high energy highest occupied molecular orbitals (HOMO) can donate electron pairs to other species; whereas Lewis acids can accept electron pairs owing to the presence of their lowest unoccupied molecular orbitals (LUMO). ${ }^{2,3}$ As per the previously conceived concepts of Bronsted acids and bases, Lewis acid-bases also combine together resulting in neutralisation. However, in these cases, new Lewis acid-base adducts are formed rather than salt and water. The concept of Lewis acid-base behaviour of molecules is one of the most fundamental tenets of modern chemistry. A major part of main group chemistry and almost the entire domain of transition metals coordination chemistry can be

*For correspondence understood and generalised in terms of Lewis acid-base concepts. $^{1-3}$

\subsection{FLPs: Observations from the past and modern breakthrough}

If there is a rule, there must be exceptions. From time to time, researchers have observed the limitations of Lewis acid-base adduct formations. In 1942, Brown et al. found that the formation of Lewis acid-base adducts between pyridines and simple boranes was not observed for lutidine (1) and $\mathrm{BMe}_{3}{ }^{4}$ However, under similar conditions, lutidine forms a Lewis acid-base adduct (2) with $\mathrm{BF}_{3}$ (scheme 1). After examining the molecular models of these compounds, they attributed this result to the steric encounter of the methyl groups of $\mathrm{BMe}_{3}$ and the ortho-methyl groups of Lutine. In 1959, Wittig and Benz noticed that in situ generated benzynes (1,2-dedihydrobenzene, 3 from o-fluorobromobenzene), with a mixture of $\mathrm{PPh}_{3}$ (Lewis base) and $\mathrm{BPh}_{3}$ (Lewis acid) gives the o-phenylene-bridged phosphonium borate (4) (scheme 2). ${ }^{5,6}$

In 1966, Tochtermann observed the formation of the trapped product 6 (scheme 2) upon addition of $\mathrm{BPh}_{3}$ to the butadiene monomer/trityl anion initiator mixture. ${ }^{7}$ Whereas, other Lewis acids would result in the polymerisation of butadiene, the bulkier $\mathrm{BPh}_{3}$ failed in this case. Clearly, the bulky Lewis acids and bases behaved in a different manner compared to classical Lewis acids and bases. Tochtermann described such non-quenched Lewis pairs using the German term 'antagonis-tisches 
Paar'. However, the undestanding of the reactivity of such 'Lewis Pairs' (LPs) and their applications had to wait until 2006 when Stephan and co-workers, ${ }^{8}$ for the first time, demonstrated the utilizations of the reactivity of such FLPs (scheme 3$){ }^{8}$

The zwitterionic salt 7 obtained from aromatic nucleophilic substitution reaction of $\mathrm{B}\left(\mathrm{C}_{6} \mathrm{~F}_{5}\right)_{3}$ with dimesitylphosphine, was treated with $\mathrm{Me}_{2} \mathrm{SiHCl}$, yielding $\mathbf{8}$ cleanly. The compound $\mathbf{8}$ at that time was considered to be a rare example of a system containing both protic and hydridic fragments. The species was air and moisture stable and by itself quite robust. However, heating of the species near $423 \mathrm{~K}$ resulted in elimination of $\mathrm{H}_{2}$ and formation of compound $\mathbf{9}$. The structure of $\mathbf{9}$ was confirmed with X-ray diffraction analysis (figure 1). The sterically congested compound

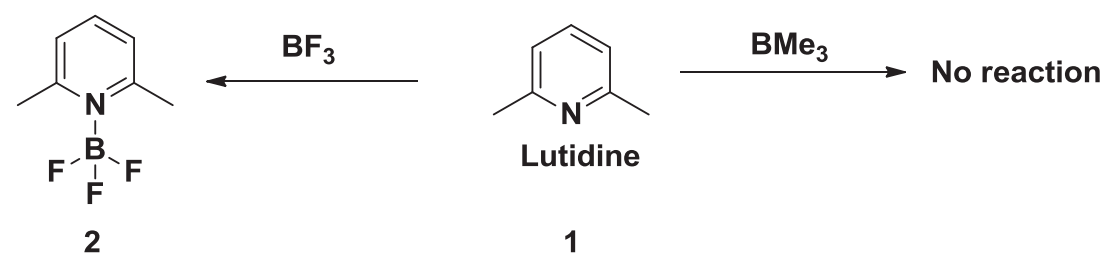

Scheme 1. Reaction of lutidine with different boranes.<smiles>Fc1ccccc1Br</smiles>

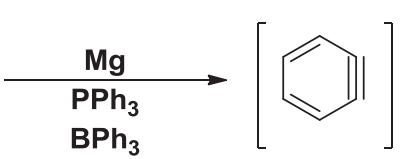

3

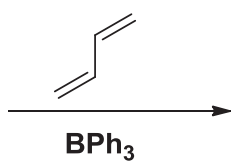

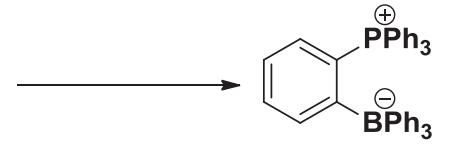

4

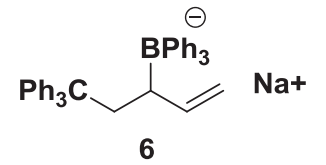

Scheme 2. Behaviours of bulky Lewis acids and bases.

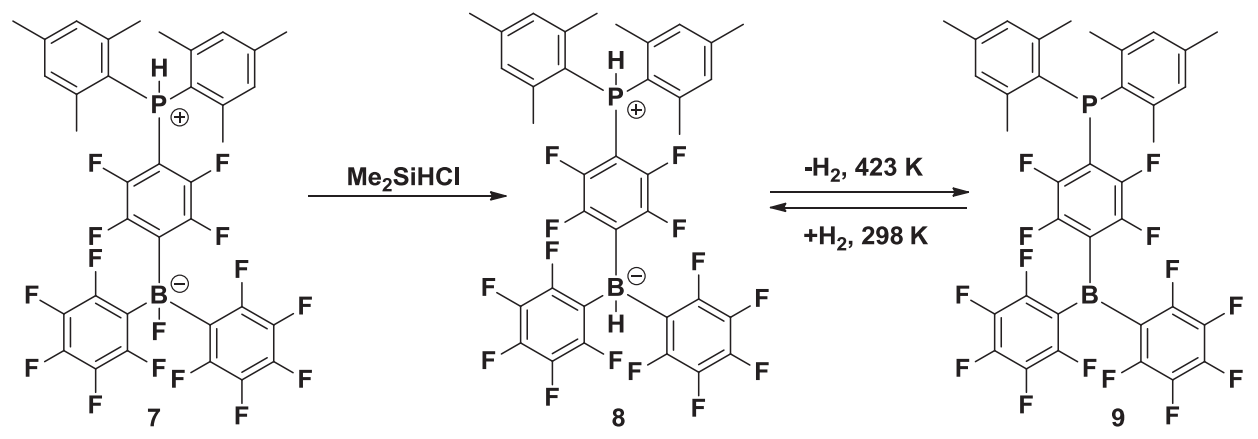

Scheme 3. Dihydrogen activation by phosphine-borane based FLP.
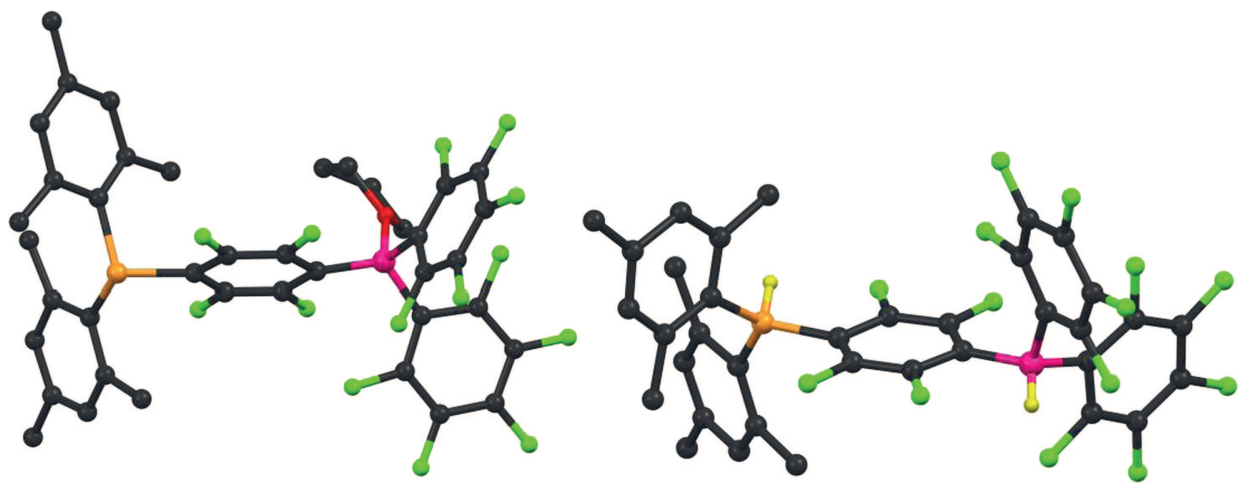

Figure 1. Molecular structures of THF coordinated 9 and 8. (Colour codes; $\mathrm{C}=\mathrm{Black}$, $\mathrm{P}=$ Orange, $\mathrm{B}=$ Magenta, $\mathrm{F}=$ Green, $\mathrm{H}=$ Yellow, $\mathrm{O}=$ Red; only relevant hydrogens are shown for clarity). 


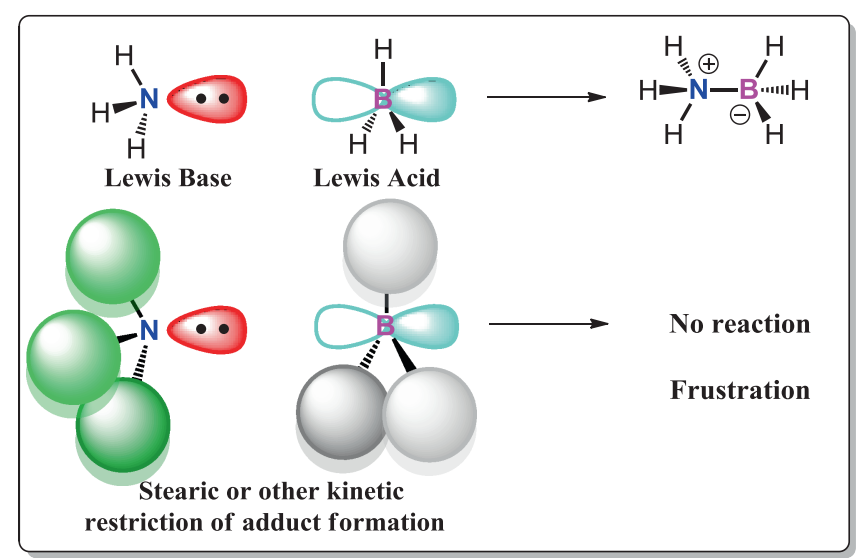

Figure 2. Lewis acid-base interactions between ammonia and borane (top) and sterically encumbered FLPs (bottom).

was found to be monomeric in solution with no signs of dimerisations or higher aggregations and could be described as a sterically 'Frustrated Lewis pair' (figure 2). Surprisingly, the significant finding was that the addition of $\mathrm{H}_{2}$ to the phosphinoborane $\mathbf{9}$ at 298 $\mathrm{K}$ resulted in rapid and facile formation of $\mathbf{8}$. The reaction could also be monitored by naked eye as the dark red colour of $9\left(\lambda_{\max }=455 \mathrm{~nm} ; \varepsilon=487 \mathrm{~L}\right.$ $\mathrm{cm}^{-1} \mathrm{~mol}^{-1}$ ) disappears with formation of colourless 8 . This represented the first example of a non-transition metal system which could both release and take up dihydrogen. This unique reactivity was undoubtedly a result of the combination of sterically crowded strong Lewis acid and Lewis base where steric demands prevent the classical adduct formation. Such FLPs have emerged as one of the most promising classes of catalysts in modern chemistry in the last few years. Here, we will concentrate on the design principles of such
FLPs and the reactivity of such systems in the activation of small molecules.

\subsection{Mechanism and applications}

The mechanisms of such reactivity in FLP systems are still not well-understood. Although our concepts about transition metal based dihydrogen activations are well-established in literature, the FLPs are still not bound by a single rule. Two alternative reactivity models have been proposed to qualitatively describe the heterolytic cleavage of $\mathrm{H}_{2}$ by FLPs (figure 3 ). Both models assume that the course of the reaction passes through intermediates consisting of pre-organised Lewis acidbase partners. ${ }^{9,10}$ The electron transfer (ET) model suggests that hydrogen activation is accompanied by synergistic e-donation with the concurrent involvement of active centres and the bridging dihydrogen, similar to transition-metal-based systems. On the other hand, the electric field (EF) model proposes that the heterolytic bond breaking occurs as a result of polarization of $\mathrm{H}_{2}$ by the strong EF present in the cavity of the reactive species. Recent study by Paìpai and co-workers suggests that the EF model might be improper to understand the actual occurrences at a molecular level. ${ }^{10}$ The ET model suggests bond weakening via orbital overlap at intermediate steps based on computational studies (figure 4).

The primary drawback of the metal-free FLP systems is their stoichiometric reaction processes rather than catalytic activity. However, this drawback has been overcome in recent years. Metal-free hydrogenation of unsaturated compounds using FLP systems is now
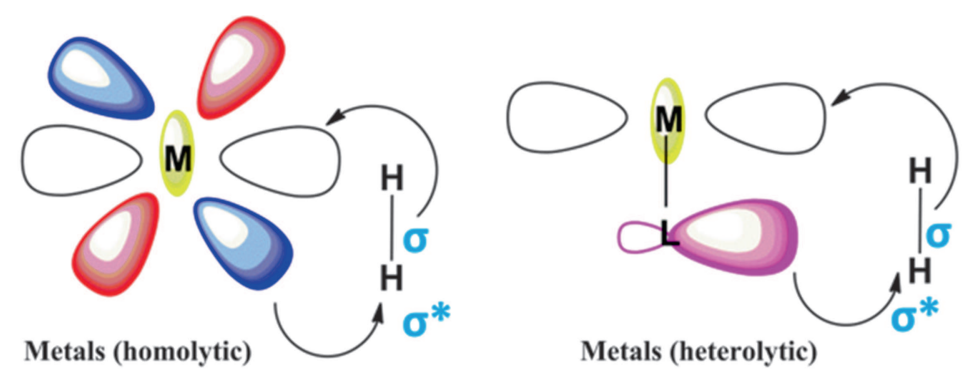

Metals (heterolytic)
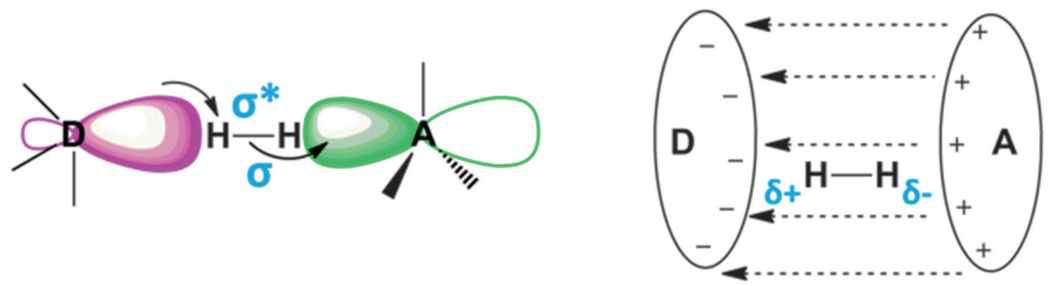

ET Model

EF Model

Figure 3. Proposed mechanisms of heterolytic dihydrogen activation by FLPs compared to transition-metal-based systems (left). 


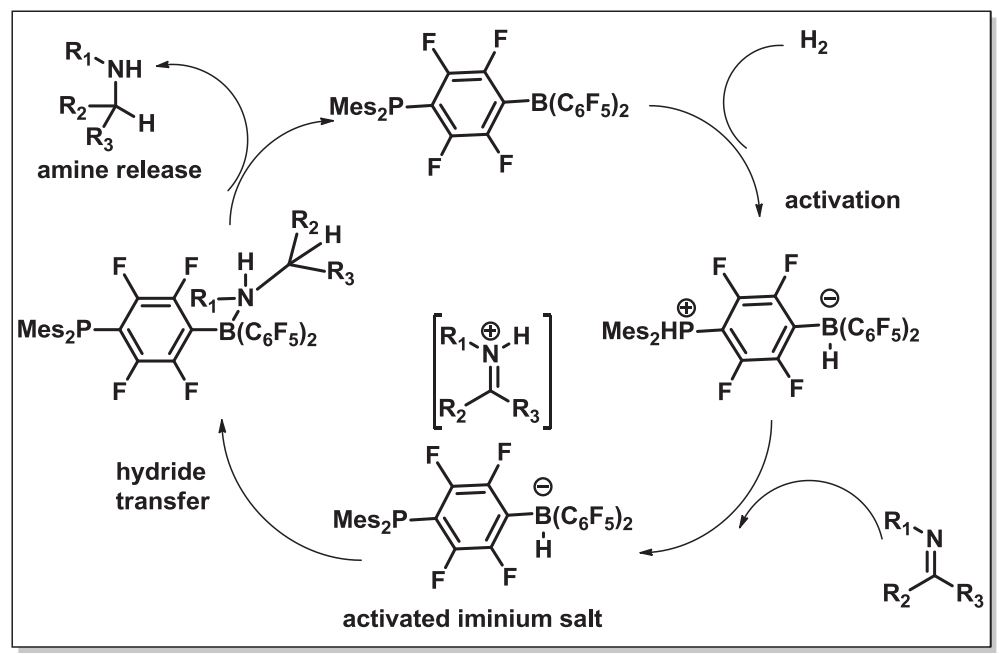

Figure 4. Proposed mechanism of catalytic reduction of amine by 9 .

a well-studied subject in literature. Stephan and coworkers have shown that FLPs such as 9 (5 mol\%) can catalytically reduce imines under mild conditions (figure 4). Imines with sterically encumbered nitrogen are reduced cleanly in high yield at $80-120^{\circ} \mathrm{C}$ under $\mathrm{H}_{2}$ pressure of 1-5 atm. The imine could be easily separated using filtration through a plug of silica gel, affording the pure product. This catalyst has been successfully commercialised in recent times and has found its way into modern chemical laboratories.

\section{Designs of frustrated Lewis pairs}

\subsection{Phosphine-borane systems}

The observations of Stephan and co-workers stirred curiosity about the generalisations of such heterolytic $\mathrm{H}_{2}$ activation by FLPs. In this regard, studies were performed on the mixtures of sterically congested phosphines $\mathrm{PR}_{3}\left(\mathrm{R}={ }^{\mathrm{t}} \mathrm{Bu}, \mathrm{C}_{6} \mathrm{H}_{2} \mathrm{Me}_{3}\right)$ and $\mathrm{B}\left(\mathrm{C}_{6} \mathrm{~F}_{5}\right)_{3}$ (scheme 4) in solution. ${ }^{11}$

The mixtures did not show any signature of adduct formation. NMR studies also showed the presence of individual constituents even on cooling to $223 \mathrm{~K}$. However, their exposure to $\mathrm{H}_{2}$ gas resulted in a rapid generation of the salt $\mathbf{1 0}(\mathbf{1 0 a}$ and $\mathbf{1 0 b})$ resulting from the

$$
R_{3} P+B\left(C_{6} F_{5}\right)_{3}
$$

\section{$\left[\mathrm{R}_{3} \mathrm{PH}\right]+\left[\mathrm{HB}\left(\mathrm{C}_{6} \mathrm{~F}_{5}\right)_{3}\right]-10 \mathrm{a}, \mathrm{b}$}

$$
\begin{aligned}
& 10 a \mathrm{R}=\mathrm{C}_{6} \mathrm{H}_{2} \mathrm{Me}_{3} \\
& 10 \mathrm{~b} \mathrm{R}=\mathrm{tBu} \\
& \mathrm{tBu}_{3} \mathrm{P}+\mathrm{BPh}_{3}
\end{aligned}
$$$$
[\mathrm{tBuPH}]+\left[\mathrm{HBPh}_{3}\right]-11
$$

Scheme 4. Studies on phosphine-borane-based Frustrated Lewis Pair. heterolytic cleavage of $\mathrm{H}_{2}$. The reaction of $\mathrm{BPh}_{3}$ and ${ }^{t} \mathrm{Bu}_{3} \mathrm{P}$ with $\mathrm{H}_{2}$ was found to give $\mathbf{1 1}$ in only $33 \%$ yield. Analogous combinations of $\left(\mathrm{C}_{6} \mathrm{H}_{2} \mathrm{Me}_{3}\right)_{3} \mathrm{P}$ and $\mathrm{BPh}_{3}$, $\left(\mathrm{C}_{6} \mathrm{~F}_{5}\right)_{3} \mathrm{P}$ and $\mathrm{B}\left(\mathrm{C}_{6} \mathrm{~F}_{5}\right)_{3}$ or ${ }^{\mathrm{t}} \mathrm{Bu}_{3} \mathrm{P}$ and $\mathrm{B}\left(\mathrm{C}_{6} \mathrm{H}_{2} \mathrm{Me}_{3}\right)_{3}$ did not react with $\mathrm{H}_{2}$, despite the fact that no such Lewis pair adducts were formed in these cases. It was concluded that the combined strength of Lewis acidity and basicity is an essential requirement for effective $\mathrm{H}_{2}$ activation by FLPs.

Apart from these trials, the Erker group, in search of similar $\mathrm{H}_{2}$ activating systems, developed linked phosphine-borane (scheme 5). ${ }^{12}$ The reaction of bulky (dimesityl)vinylphosphine $\mathbf{1 2}$ with $\mathrm{HB}\left(\mathrm{C}_{6} \mathrm{~F}_{5}\right)_{2}$ resulted in formation of clean hydroboration product $\mathbf{1 3 a} / \mathbf{1 3 b}$. Theoretical analysis suggested that the global minima of this monomeric bifunctional system feature a four-membered heterocyclic structure with weak $\mathrm{P}-\mathrm{B}$ interaction (at distance 2.21 $\mathrm{\AA}$ ). Upon exposure to $\mathrm{H}_{2}$, 13a immediately produces the zwitterionic product 14 as a white precipitate. Compound 14, shows typical hydrido borate reactivity and reduces benzaldehyde stoichiometrically to give benzylalcohol derivative $\mathbf{1 5}$. Prompted by this development, similar alkenylenelinked phosphine/borane systems were also studied.

Later, the second reported system capable of metalfree reversible activation of $\mathrm{H}_{2}$ came from a Lewis pair based on 1,8-bis(diphenylphosphinonaphthalene) (16) (scheme 6). ${ }^{13}$ Combining 16 with $\mathrm{B}\left(\mathrm{C}_{6} \mathrm{~F}_{5}\right)_{3}$ in a $1: 1$ molar ratio resulted in a Lewis-pair that activated $\mathrm{H}_{2}$ (1.5 bar) to yield the phosphonium hydridoborate salt 17 (scheme 6). Phosphorus ${ }^{31}$ NMR data showed the rapid exchange of proton between the two phosphine groups in 17. The zwitterion 17 liberated $\mathrm{H}_{2}$ at $333 \mathrm{~K}$ regenerating the Lewis pair mixture.

Later, Stephan et al. targeted modifications of the borane partners to preclude attack by nucleophilic 


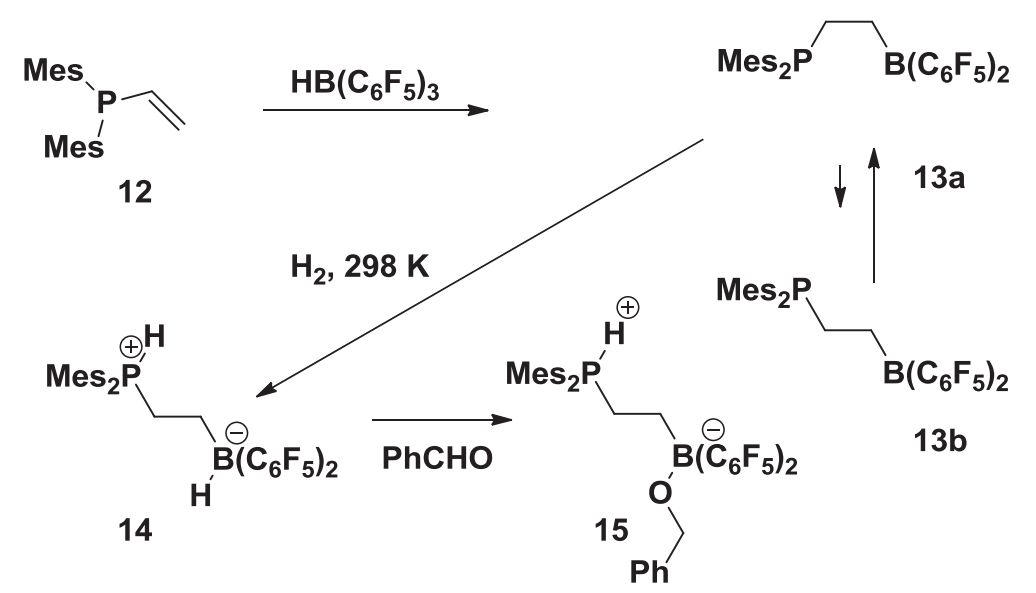

Scheme 5. Dihydrogen activation by linked phosphine-boranes.

\section{$B\left(C_{6} F_{5}\right)_{3}$}

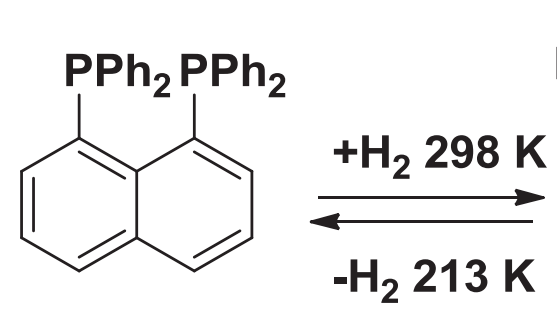

16
$\left[\mathrm{HB}\left(\mathrm{C}_{6} \mathrm{~F}_{5}\right)_{3}\right]-$<smiles>Pc1cccc2cccc(P)c12</smiles>

17
Scheme 6. Reversible dihydrogen activation by 1,8-bis(diphenylphosphinonaphthalene)-based FLP.

phosphine in its para position and yet to be Lewis acidic enough to effect $\mathrm{H}_{2}$ activation. Thus, the borane $\mathrm{B}\left(p-\mathrm{C}_{6} \mathrm{~F}_{4} \mathrm{H}\right)_{3}$ was prepared and studied (scheme 7). ${ }^{14}$ This borane in combination with $\mathrm{PR}_{3}\left(\mathrm{R}={ }^{\mathrm{t}} \mathrm{Bu}, \mathrm{Cy}\right.$, $o-\mathrm{C}_{6} \mathrm{H}_{4} \mathrm{Me}$ ) rapidly activates $\mathrm{H}_{2}$ at $298 \mathrm{~K}$ yielding the zwitterionic salts $\left(\mathrm{R}={ }^{\mathrm{t}} \mathrm{Bu} \mathbf{1 8 a}, \mathrm{Cy} \mathbf{1 8 b}, o-\mathrm{C}_{6} \mathrm{H}_{4} \mathrm{Me}\right.$ $18 c)$. 18c behaves differently from other zwitterionic salts and loses $\mathrm{H}_{2}$ under vacuum at $298 \mathrm{~K}$. It was only $85 \%$ complete after 9 days at $298 \mathrm{~K}$. However, at $353 \mathrm{~K}$, this reaction was completed in $12 \mathrm{~h}$.

The previously demonstrated examples are based on the concepts of unquenched electronic frustration of donor and acceptor sites. However, Stephan and co-workers also investigated the possibilities of FLPs where such fragments are directly bound to each other (scheme 8). ${ }^{15}$ They prepared the phosphido-boranes 19 $(\mathrm{R}=\mathrm{Et}, 1 \mathrm{19} \mathbf{a} ; \mathrm{R}=\mathrm{Ph}, \mathbf{1 9 b})$ and $20(\mathrm{R}=\mathrm{Cy}, \mathbf{2 0 a}$; $\mathrm{R}={ }^{\mathrm{t}} \mathrm{Bu}, \mathbf{2 0 b}$ ) and showed that sterically undemanding substituents on phosphorus resulted in the formation of dimeric products; whereas more sterically demanding groups gave monomeric species (figure 5), which retain the donor and acceptor properties of phosphine and borane, respectively (scheme 8 ). In $\mathbf{2 0 b}$, the $\mathrm{B}-\mathrm{P}$ distance is $1.786(4) \AA$. This compound reacts slowly with $\mathrm{H}_{2}$ at $333 \mathrm{~K}$ affording phosphine-borane adduct 21. The B-P distance in 21 is (1.966(9) $\AA$ ) dramatically greater than in $\mathbf{2 0 b}$ (figure 5). The dimeric<smiles>Cc1ccccc1P(c1ccccc1C)c1ccccc1C</smiles>

Scheme 7. Reversible dihydrogen activation by B $\left(\mathrm{p}-\mathrm{C}_{6} \mathrm{~F}_{4} \mathrm{H}\right)_{3}$-based FLP.

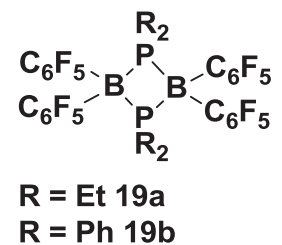

$$
\begin{aligned}
& \underbrace{C_{6} F_{5}}_{P^{\prime}-B^{\prime}} \\
& R^{\prime} C_{6} F_{5} \\
& R=C_{2} 20 a \\
& R=t B u 20 b
\end{aligned}
$$

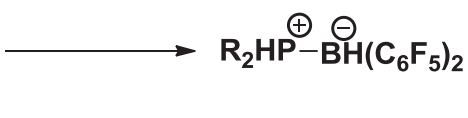

$$
\mathrm{R}=\mathrm{tBu} \quad 21
$$

Scheme 8. Dihydrogen activation by phosphido-borane-based FLP. 
phosphido-boranes did not show any reaction with $\mathrm{H}_{2}$ under similar circumstances.

In 2010, Klankermayer and co-workers included the element of chirality in this newly born concept of FLPs (scheme 9). ${ }^{16}$ In their studies, starting from $(1 \mathrm{R}, 4 \mathrm{R})$ 1,7,7-trimethyl-2-phenylbicyclo[2.2.1]hept-2-ene (22), they prepared chiral Lewis acids $\mathbf{2 3}$ and $\mathbf{2 4}$ via hydroboration reaction with $\mathrm{HB}\left(\mathrm{C}_{6} \mathrm{~F}_{5}\right)_{2}$. A detailed investigation revealed that $\mathbf{2 3}$ splits $\mathrm{H}_{2}$ faster than $\mathbf{2 4}$ in presence of ${ }^{t} \mathrm{Bu}_{3} \mathrm{P}$ in pentane. This observation enabled separation of the two zwitterionic salts crystals (25 and 26) via kinetically controlled product formation. The zwitterionic salts were effectively used as catalysts for enantioselective hydrogenation of olefins. These results boosted the research of chiral FLPs for practical applications as catalysts.

Recently in 2013, Erker and co-workers reported non-interacting, vicinal frustrated P/B-Lewis pairs anchored at the norbornene framework (scheme 10). ${ }^{17 \mathrm{a}}$ In their approach, starting from dimesitylnorbornenylphosphane, they prepared compound 27 via hydroboration with Piers' borane $\left[\mathrm{HB}\left(\mathrm{C}_{6} \mathrm{~F}_{5}\right)_{2}\right]$. The vicinal FLP 27 was shown by X-ray crystallography and spectroscopy to be a rare example of a non-interacting intramolecular pair of a Lewis acid-base pair. Under ambient temperatures, 27 rapidly cleaves $\mathrm{H}_{2}$ to form the zwitterionic salt 28 (figure 6). Optically active chiral Lewis pairs based on axially chiral systems, i.e.,

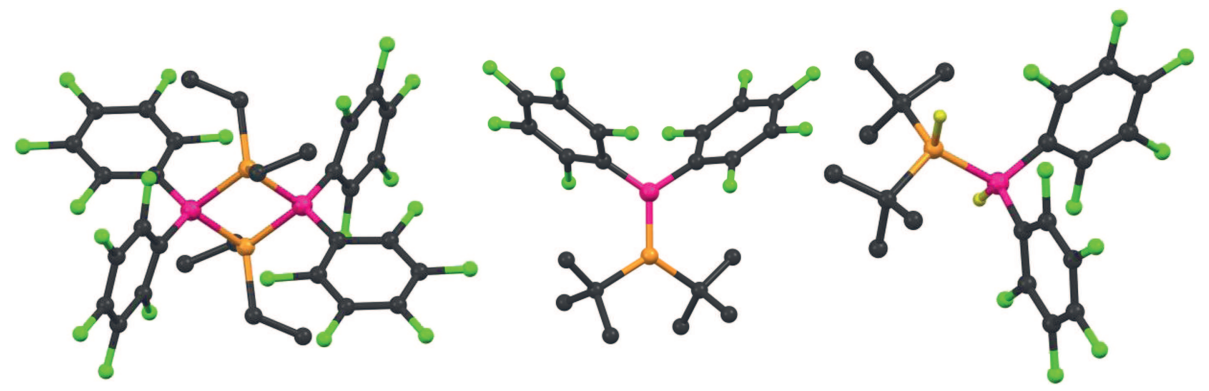

Figure 5. Molecular structures of 19a, 20b and 21. (Colour codes; $\mathrm{C}=$ Black, $\mathrm{P}=$ Orange, $\mathrm{B}=$ Magenta, $\mathrm{F}=$ Green, $\mathrm{H}=$ Yellow; only relevant hydrogens are shown for clarity.)
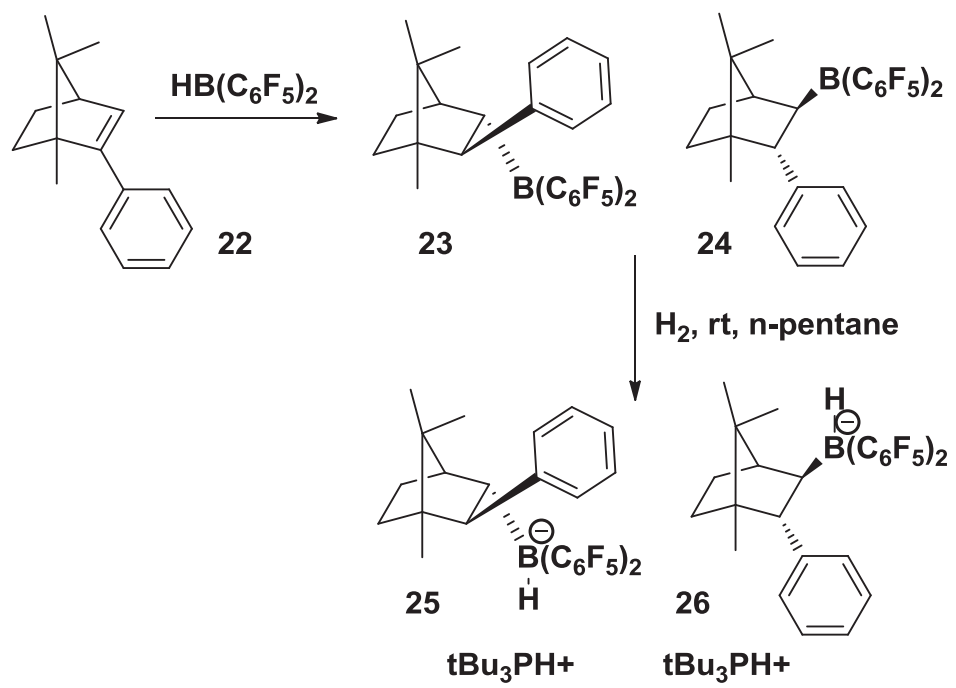

Scheme 9. Dihydrogen activation by a chiral FLP.

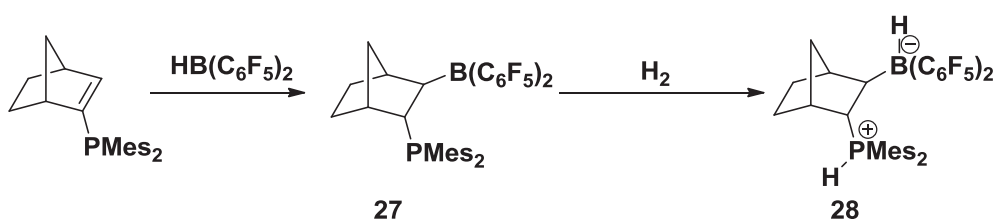

Scheme 10. Dihydrogen activation by a vicinal non-interacting FLP. 


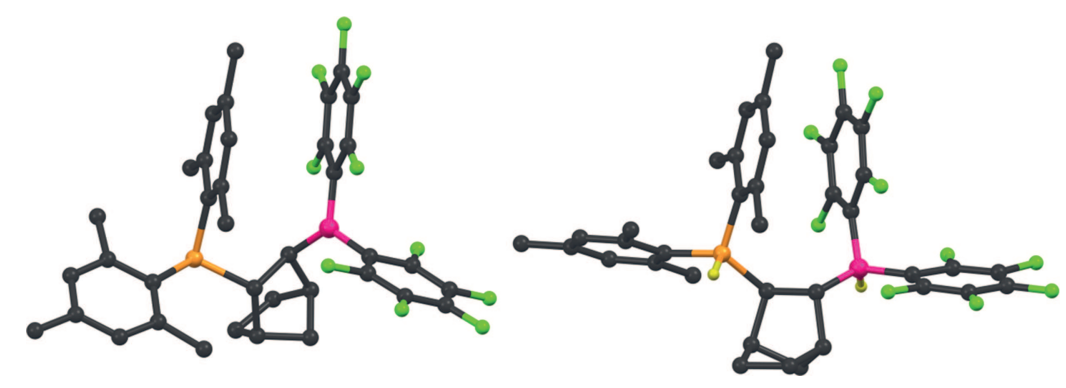

Figure 6. X-ray-molecular structures of $\mathbf{2 7}$ and 28. (Colour codes; $\mathrm{C}=$ Black, $\mathrm{P}=$ Orange, $\mathrm{B}=$ Magenta, $\mathrm{F}=$ Green, $\mathrm{H}=$ Yellow; only relevant hydrogens are shown for clarity).

ferrocene scaffolds have also been demonstrated by Thilagar et al in $2013 .{ }^{17 \mathrm{~b}}$

\subsection{Amine-borane systems}

As reported by Reiger and co-workers in 2008, reaction of $\mathrm{B}\left(\mathrm{C}_{6} \mathrm{~F}_{5}\right)_{3}$ with ${ }^{\mathrm{i}} \mathrm{Pr}_{2} \mathrm{NEt}$ and ${ }^{\mathrm{i}} \mathrm{Pr}_{2} \mathrm{NH}$ gives $1: 1$ mixture of corresponding ammonium salts 29 and 30, respectively (scheme 11). ${ }^{18 \mathrm{a}-\mathrm{b}}$ These reactions also produce zwitterionic products $\mathbf{3 1}$ and $\mathbf{3 2}$ resulting from amine dehydrogenation. However, exposure of mixtures of ${ }^{i} \mathrm{Pr}_{2} \mathrm{NH}$ or $\mathrm{Me}_{4} \mathrm{C}_{5} \mathrm{H}_{6} \mathrm{NH}$ with $\mathrm{B}\left(\mathrm{C}_{6} \mathrm{~F}_{5}\right)_{3}$ to $\mathrm{H}_{2}$ produces quantitatively the ammonium borates $\mathbf{3 0}$ and $\mathbf{3 3}$ (scheme 11). Also, the Repo and Rieger group reported a linked amine-borane 34, which exhibits reversible $\mathrm{H}_{2}$ activation via formation of $\mathbf{3 5}$ (scheme 11). ${ }^{18 \mathrm{c}}$

In 2009, Stephan et al. explored the reactivities of Lutidine- $\mathrm{B}\left(\mathrm{C}_{6} \mathrm{~F}_{5}\right)_{3}$ pair. ${ }^{19}$ This combination was found to behave as a boundary between classical Lewis pairs and FLPs (scheme 12). Unlike previously reported systems, lutidine and $\mathrm{B}\left(\mathrm{C}_{6} \mathrm{~F}_{5}\right)_{3}$ undergo reversible adduct formation (36) such as classical Lewis pairs (figure 7). However, the reactivity of the system towards $\mathrm{H}_{2}$ is not diminished. Upon exposure to $\mathrm{H}_{2}$ atmosphere, the zwitterionic salt (37) formation was observed with $87 \%$ yield. Also, the classical Lewis adduct causes ring opening of THF resulting in formation of $\mathbf{3 8}$ (scheme 12). These results indicate that the two

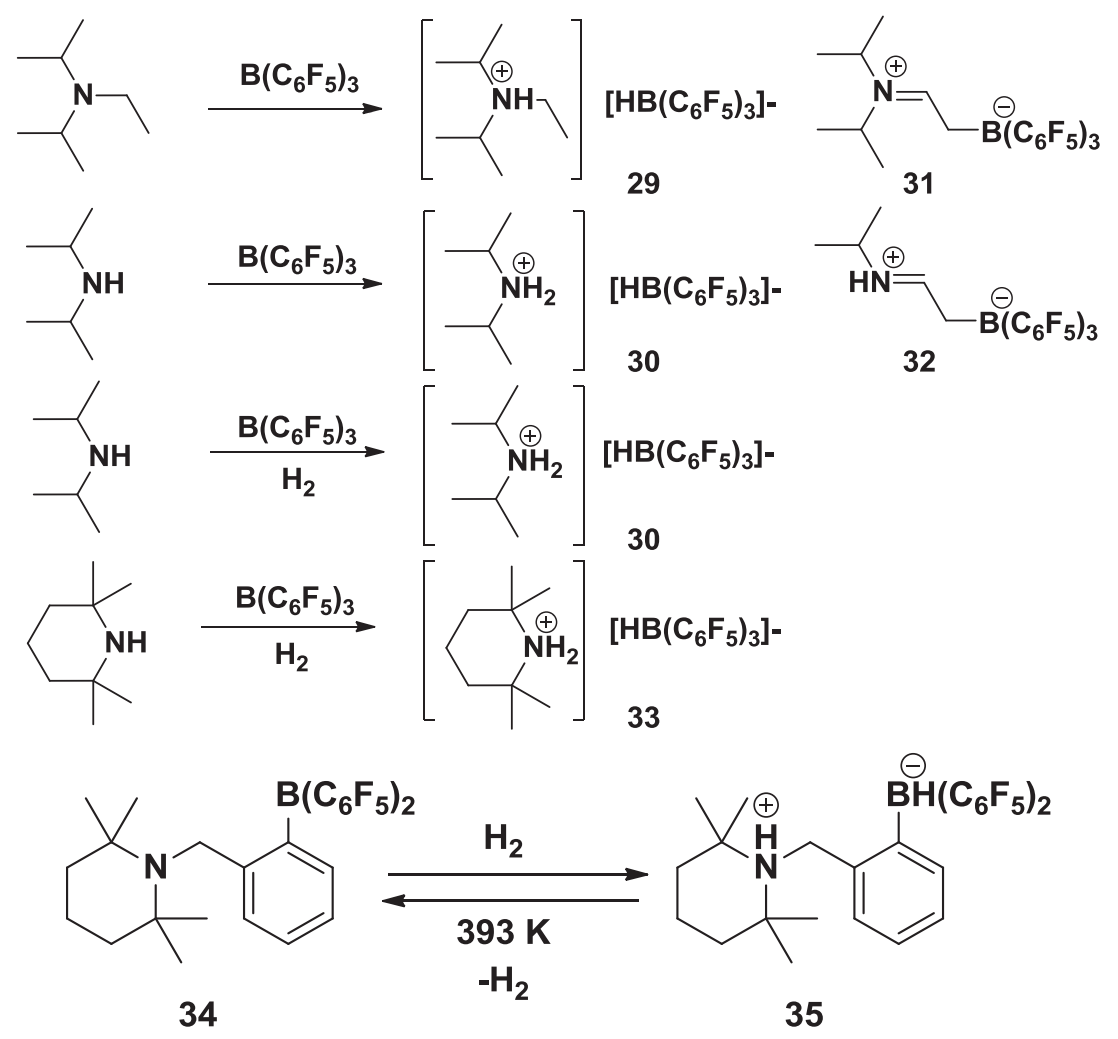

Scheme 11. Dihydrogen activation by a amine--borane-based FLPs. 
<smiles>Cc1cccc(CC=Cc2ccc(C)nc2C)c1</smiles>

\section{$\left[\mathrm{HB}\left(\mathrm{C}_{6} \mathrm{~F}_{5}\right)_{3}\right]-\quad \mathrm{B}\left(\mathrm{C}_{6} \mathrm{~F}_{5}\right)_{3}$}

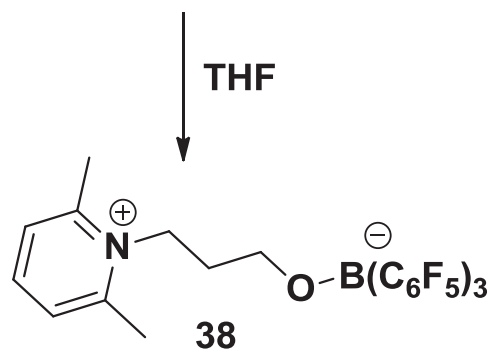

Scheme 12. Dihydrogen activation by lutine- $\mathrm{B}\left(\mathrm{C}_{6} \mathrm{~F}_{5}\right)_{3}$ pair.
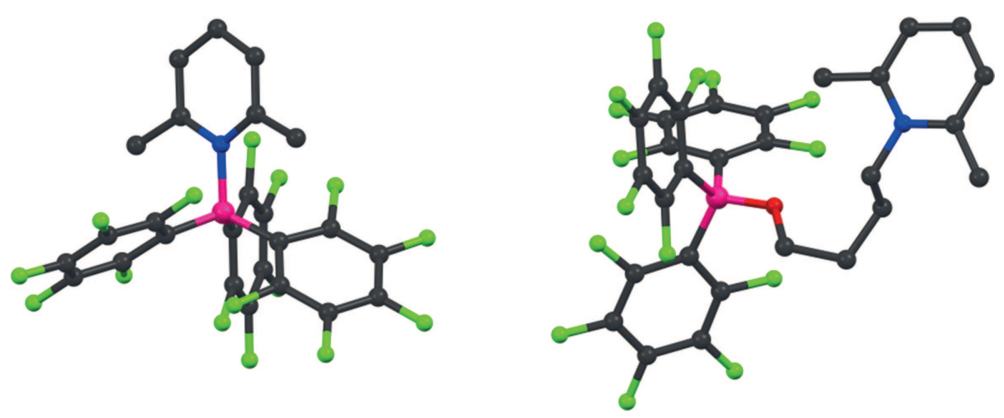

Figure 7. Molecular structures of $\mathbf{3 6}$ and 38. (Colour codes; $\mathrm{C}=$ Black, $\mathrm{N}=$ Blue, $\mathrm{B}=$ Magenta, $\mathrm{F}=$ Green, $\mathrm{H}=$ Yellow; only relevant hydrogens are shown for clarity).

different types of reactivities of Lewis pairs may not be mutually exclusive.

In 2010, Tamm and co-workers successfully extended the versatality of amine-borane-based FLPs with close proximity (scheme 13). ${ }^{20}$ They showed that the reaction of Piers' borane with 3,5-di-tert-butyl-1Hpyrzole (39) the (resulted in formation) of zwitterionic pyrazoliumborate trans-40, which after dehydrogenation by use of carbine-borane Lewis pair 41, gave bifunctional pyrazolylborane 42 (scheme 13). The yellowcoloured FLP $\mathbf{4 2}$ rapidly decolourises upon exposure to $\mathrm{H}_{2}$ at room temperature resulting in formation of trans40 and cis-40. Gradually, reversibility of the reaction allows the complete conversion of cis-40 to trans-40.

In 2011, Ashley and co-workers prepared tris[3,5bis(trifluoromethyl)phenyl]borane $\mathbf{4 3}$ and 2,2,6,6-tetramethylpiperidine-derived FLP system (scheme 14). ${ }^{21}$ The mixture upon exposure to $\mathrm{H}_{2}$ resulted in the formation of the ammonium cation $\mathbf{4 4}$ and $\left[\mu-\mathrm{H}\left(\mathrm{BArF}_{18}\right)_{2}\right]-$ (45), which was the first example of formation of bridged hydride complexes in FLP chemistry.

Another intriguing approach in amine-borane-based FLPs was reported by Stephan and co-workers

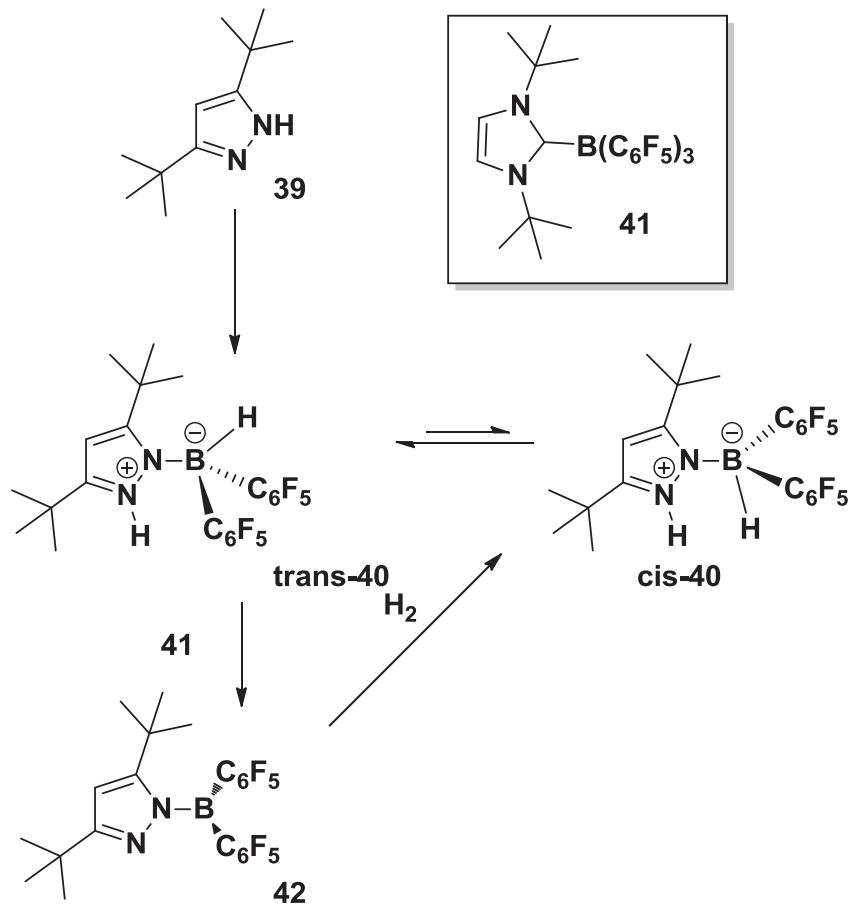

Scheme 13. Dihydrogen activation by a pyrazole-boranebased FLP. 
<smiles>CC1(C)CCCC(C)(C)N1</smiles>

43

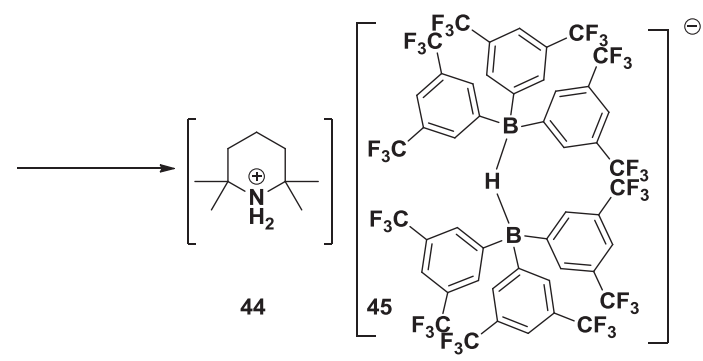

Scheme 14. Dihydrogen activation by a tris[3,5-bis(trifluoromethyl)phenyl]borane 43 and 2,2,6,6-tetramethylpiperidine-derived FLP system.

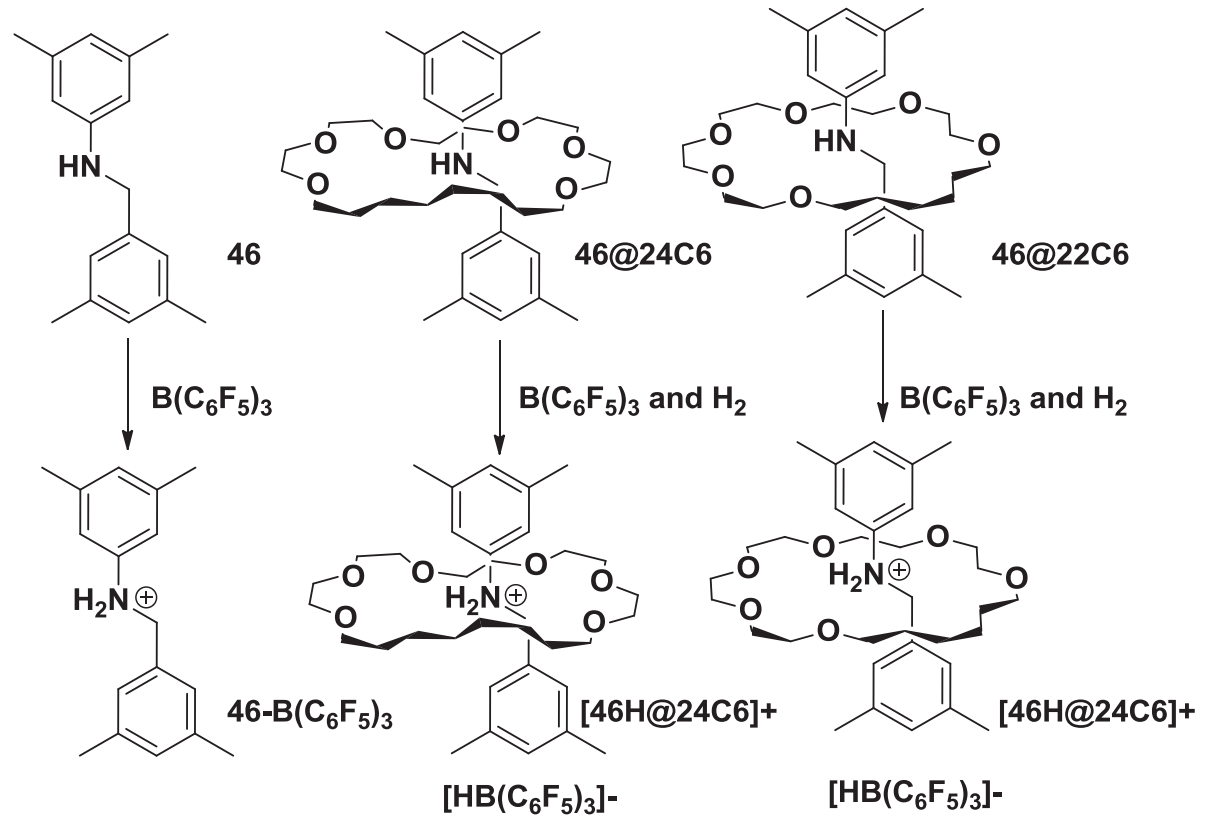

Scheme 15. Rotaxane-based FLP system.
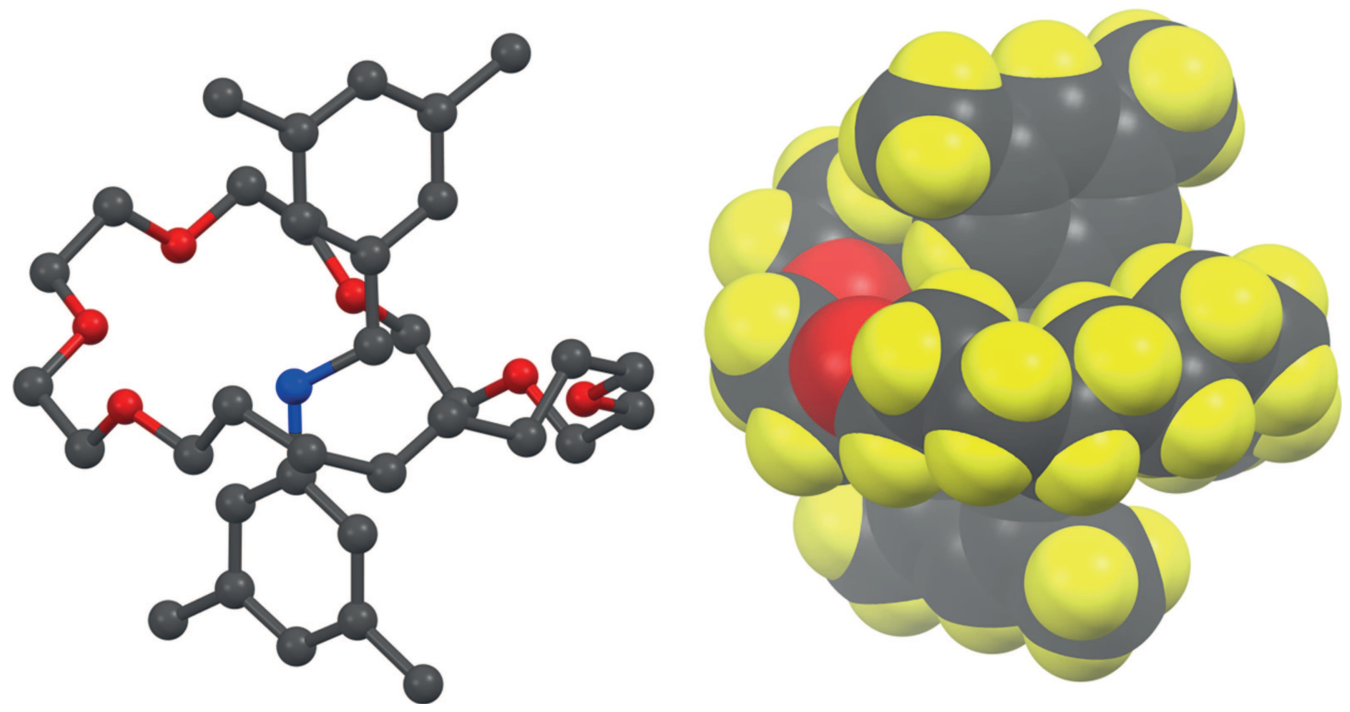

Figure 8. Molecular structures of 46@24C6 and its space-fill representation (Colour codes; C $=$ Black, $\mathrm{N}=$ Blue, $\mathrm{B}=$ Magenta, $\mathrm{F}=$ Green, $\mathrm{H}=$ Yellow). 
(scheme 15). ${ }^{22}$ In a novel approach, they sterically buried the amine functionality inside rotaxane cavities. The amine 46 bearing the 1,3-dimeethylphenyl and 1,3-dimethylbenzyl groups, was selected as the Lewis acid axle for incorporation into a [2]rotaxane. The two rotaxanes 46@24C6 and 46@22C6 with differently sized macrocyclic wheels (24 and 22 membered) and 46 as axle were prepared. The amine 46 reacts with $\mathrm{B}\left(\mathrm{C}_{6} \mathrm{~F}_{5}\right)_{3}$ in DCM forming classical Lewis adduct 46-B $\left(\mathbf{C}_{6} \mathbf{F}_{5}\right)_{3}$. However, 46@24C6 reacts with $\mathrm{H}_{2}$ (4 atm) in presence of $\mathrm{B}\left(\mathrm{C}_{6} \mathrm{~F}_{5}\right)_{3}$ in toluene (scheme 15) to give $[\mathbf{4 6 H} @ \mathbf{2 4 C 6}]+\left[\mathbf{H B}\left(\mathbf{C}_{6} \mathbf{F}_{5}\right)_{3}\right](61 \%$ yield $)$; whereas, 46 @ $22 \mathrm{C} 6$ reacts with $\mathrm{H}_{2}(4 \mathrm{~atm})$ in presence of $\mathrm{B}\left(\mathrm{C}_{6} \mathrm{~F}_{5}\right)_{3}$ in hexane to give $[\mathbf{4 6 H} @ \mathbf{2 2} \mathbf{C 6}]^{+}\left[\mathbf{H B}\left(\mathbf{C}_{6} \mathbf{F}_{5}\right)_{3}\right]^{-}(60 \%)$ (scheme 15). These results demonstrate that a sterically unencumbered base (figure 8) can be included in a FLP reactivity region without any covalent modification.

\subsection{Carbene-borane systems}

In 2007, Bertrand and co-workers demonstrated that the alkylaminocarbene $\mathbf{4 7}$ reacts with $\mathrm{H}_{2}$ as well as

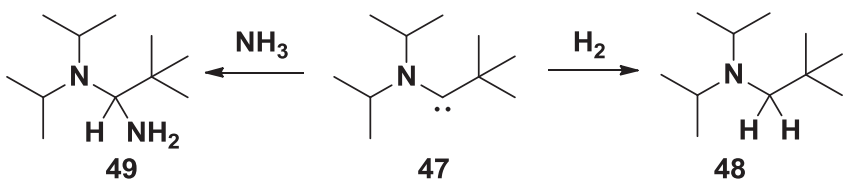

Scheme 16. Cleavage dihydrogen and ammonia by a carbene system.
$\mathrm{NH}_{3}$ resulting in cleavage of $\mathrm{H}-\mathrm{H}$ and $\mathrm{N}-\mathrm{H}$ bonds and formation of $\mathbf{4 8}$ and $\mathbf{4 9}$, respectively (scheme 16). ${ }^{23}$

In 2008, the research groups of Stephan and Tamm independently reported the use of sterically hindered carbene and $\mathrm{B}\left(\mathrm{C}_{6} \mathrm{~F}_{5}\right)_{3}$ in FLP chemistry (scheme 17 and figure 9). ${ }^{24}$ Carbene 50, although considered bulky, forms a stable classical Lewis acid-base adduct $\mathbf{5 1}$ with $\mathrm{B}\left(\mathrm{C}_{6} \mathrm{~F}_{5}\right)$. Tamm and co-workers showed that the adduct of $\mathrm{B}\left(\mathrm{C}_{6} \mathrm{~F}_{5}\right)_{3}$ and $\left({ }^{\mathrm{t}} \mathrm{BuN}\right)_{2} \mathrm{C}_{3} \mathrm{H}_{2}(\mathbf{5 2})$ resulted in FLP 53. Upon prolonged standing, the zwitterionic compound 54 is formed. However, freshly prepared FLP mixture; upon exposure to $\mathrm{H}_{2}$ in toluene results in immediate formation of imidazolium hydridoborate salt $\mathbf{5 5}$. FLP mixture 53 also results in ring opening of THF giving 56.

\subsection{Phosphine-alane systems}

Although most of the reports on FLP deal with fluorinesubstituted electron-deficient boranes as the Lewis acid counterpart, recent efforts have been successful in utilizing other related Lewis acids in FLP chemistry. In 2010, Stephan and co-workers demonstrated the utilization of phosphine alane mixtures as effective FLP catalysts (scheme 18). ${ }^{25}$ A 1:1 solution of $\mathrm{PMes}_{3} / \mathrm{AlX}_{3}$ $(\mathrm{X}=\mathrm{Cl} \mathbf{5 7}, \mathrm{X}=\mathrm{Br} \mathbf{5 8})$ in bromobenzene results in the formation of weak Lewis adducts. When these solutions were exposed to $\mathrm{CO}_{2}$ in $\mathrm{C}_{6} \mathrm{D}_{5} \mathrm{Br}$ in sealed NMR tubes, the formation of $\mathrm{Mes}_{3} \mathrm{P}\left(\mathrm{CO}_{2}\right)\left(\mathrm{AlX}_{3}\right)(\mathrm{X}=\mathrm{Cl} \mathbf{5 9}, \mathrm{X}=\mathrm{Br}$ 60) was observed. In these compounds, the phosphines
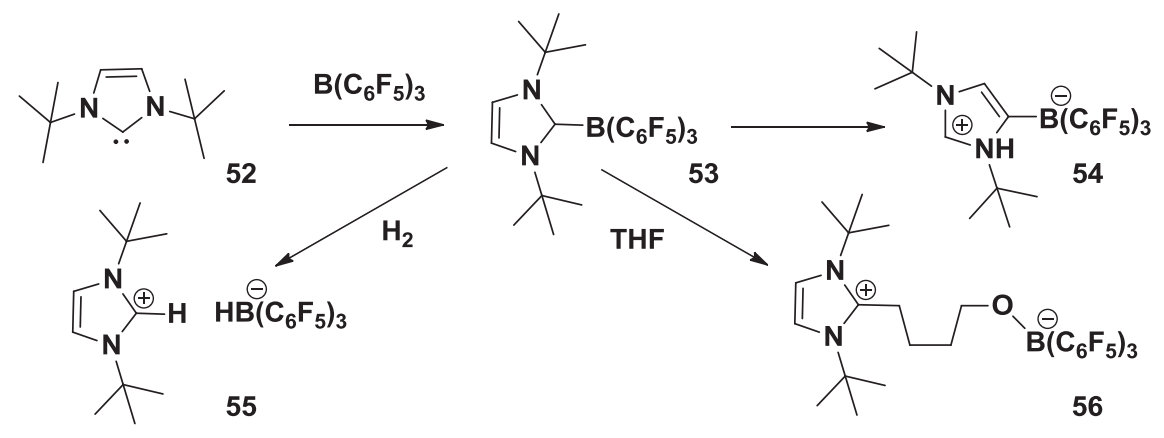

Scheme 17. NHC-derived FLP systems.
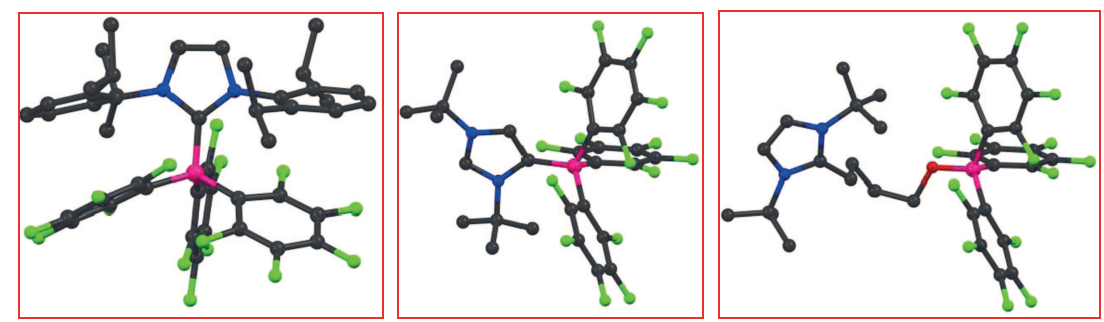

Figure 9. X-ray-obtained molecular structures of 51, 54 and 56. (Colour codes; $\mathrm{C}=$ Black, $\mathrm{N}=$ Blue, $\mathrm{B}=$ Magenta, $\mathrm{F}=$ Green, $\mathrm{H}=$ Yellow; only relevant hydrogens are shown for clarity). 


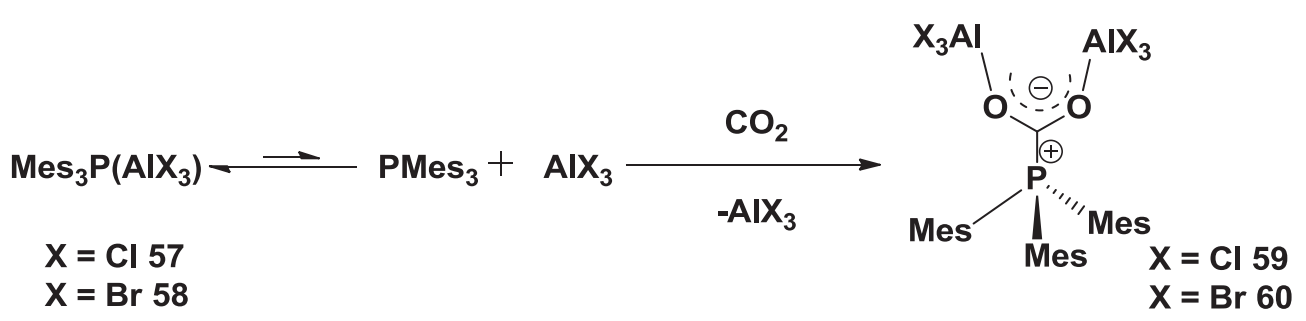

Scheme 18. Carbon dioxide activation by phosphine-alane-based FLP systems.

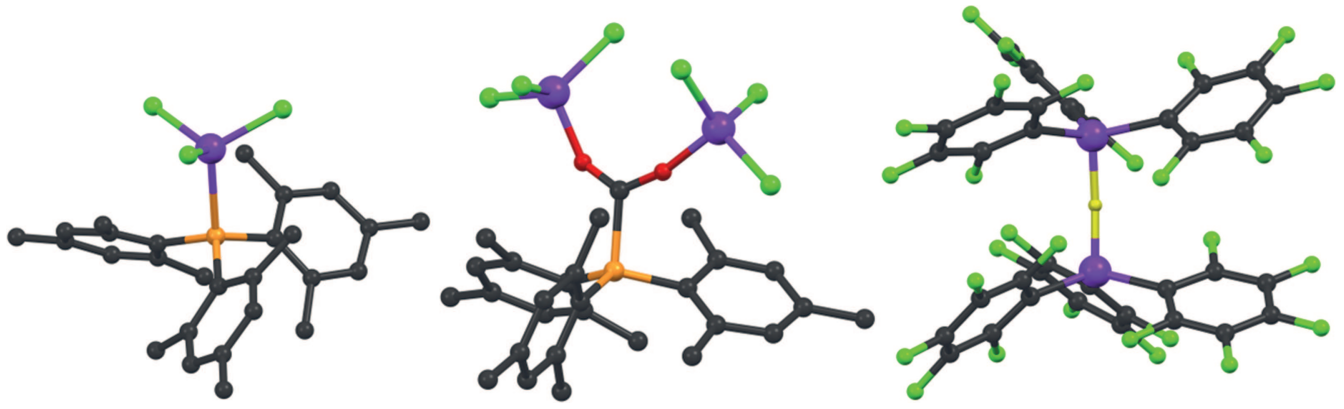

Figure 10. Molecular structures of 57, 59 and anionic part of 61. (Colour codes; $\mathrm{C}=\mathrm{Black}$, $\mathrm{P}=$ Orange, $\mathrm{Al}=$ Purple, $\mathrm{Cl} / \mathrm{F}=$ Green, $\mathrm{H}=$ Yellow; only relevant hydrogens are shown for clarity).

are bound to the $\mathrm{C}$ atom of $\mathrm{CO}_{2}$, whereas the $\mathrm{AlX}_{3}$ units are bound to the $\mathrm{O}$ atoms (figure 10). The reactions of these complexes with ammoniaborane and subsequent addition of $\mathrm{H}_{2} \mathrm{O}$ resulted in the formation of $\mathrm{MeOH}$. This type of room temperature conversion of $\mathrm{CO}_{2}$ to $\mathrm{MeOH}$ is a milestone with respect to FLP chemistry. Later in 2011, these types of FLPs were further explored for stoichiometric reduction of $\mathrm{CO}_{2}$ to $\mathrm{CO}$.

Later in 2012, phosphine-alane pairs were also successfully utilized to achieve heterolytic cleavage of $\mathrm{H}_{2}$ at room temperature conditions. ${ }^{26}$ Combining $\mathrm{tBu}_{3} \mathrm{P}$ and $\mathrm{Al}\left(\mathrm{C}_{6} \mathrm{~F}_{5}\right)_{3}$.toluene in a 1:2 ratio in fluorobenzene under $4 \mathrm{~atm}$ of $\mathrm{H}_{2}$ gave zwitterionic 61, i.e., $\left[{ }^{\mathrm{t}} \mathrm{Bu}_{3} \mathrm{PH}\right]$ $\left[(\mu-\mathrm{H})\left\{\mathrm{Al}\left(\mathrm{C}_{6} \mathrm{~F}_{5}\right)_{2}\right\}_{2}\right]$ (figure 10). Such bridging hydride formation is relatively rare in borane chemistry. Further, in 2013, Stephan and co-workers showed the utilizations of similar Lewis pairs in activation of $\mathrm{N}_{2} \mathrm{O} .{ }^{27}$ Also, similar amine-alane systems were also developed as catalysts for oligomerisations of cyanamides. ${ }^{28}$

\subsection{FLPs beyond main-group and other relevant designs}

The main appeal of FLP chemistry rests on the fact that these compounds constitute the first examples of $\mathrm{H}_{2}$ addition (or similar) catalytic reactions without the mediation of the presence of transition metals. However, in most of the cases, the practical limitations of catalytic efficiency arise from the high stability of the zwitterionic salts. It is of utmost importance that the intermediates formed during catalysis cycles must be unstable relative to product; otherwise the reaction can never reach desired completion. In 2011, Wass and co-workers proposed that such limitations might be overcome with a suitable choice of transition metal based Lewis acids (scheme 19). ${ }^{29}$ The cationic zirconocene_phosphinoaryloxide complexes $\left[\mathrm{Cp}_{2} \mathrm{ZrOC}_{6} \mathrm{H}_{4}\right.$ $\left.\mathrm{P}\left({ }^{\mathrm{t}} \mathrm{Bu}\right)_{2}\right]\left[\mathrm{B}\left(\mathrm{C}_{6} \mathrm{~F}_{5}\right)_{4}\right]$ (62) and $\left[\mathrm{Cp}^{*}{ }_{2} \mathrm{ZrOC}_{6} \mathrm{H}_{4} \mathrm{P}\left({ }^{\mathrm{t}} \mathrm{Bu}\right)_{2}\right]$ $\left[\mathrm{B}\left(\mathrm{C}_{6} \mathrm{~F}_{5}\right)_{4}\right](\mathbf{6 3})$ were synthesized by the reaction of $\mathrm{Cp}_{2} \mathrm{ZrMe}_{2}$ or $\mathrm{Cp}^{*}{ }_{2} \mathrm{ZrMe}_{2}$ with 2-(diphenylphosphino) phenol followed by protonation with [2,6-ditert-butylpyridinium $]\left[\mathrm{B}\left(\mathrm{C}_{6} \mathrm{~F}_{5}\right)_{4}\right]$ (scheme 19). These compounds can be described as transition-metal-containing versions of linked FLPs. Treatment of $\mathbf{6 3}$ with $\mathrm{H}_{2}$ under mild conditions cleaved $\mathrm{H}_{2}$ forming $\mathbf{6 3 - 2 H}$ in a fashion analogous to that for main-group FLPs. However, in contrast to main-group FLPs, 62 and $\mathbf{6 3}$ achieve this transformation in a catalytic rather than stoichiometric sense, with rates superior to those for previous highvalent catalysts.

In line with this design, in 2012, Wass and coworkers also developed FLPs consisting of cationic titanium (IV) complex $\left[\mathrm{Cp}_{2} \mathrm{TiOC}_{6} \mathrm{H}_{4} \mathrm{P}\left({ }^{\mathrm{t}} \mathrm{Bu}\right)_{2}\right]\left[\mathrm{B}\left(\mathrm{C}_{6} \mathrm{~F}_{5}\right)_{4}\right]$ 64 and neutral titanium (III) complex $\left[\mathrm{Cp}_{2} \mathrm{TiOC}_{6}\right.$ $\left.\mathrm{H}_{4} \mathrm{PH}\left({ }^{\mathrm{t}} \mathrm{Bu}\right)_{2}\right]\left[\mathrm{B}\left(\mathrm{C}_{6} \mathrm{~F}_{5}\right)_{4}\right] \mathbf{6 5}$ (figure 11). ${ }^{30}$ Both the complexes were found to be efficient catalysts for the dehydrogenation of $\mathrm{Me}_{2} \mathrm{NH}-\mathrm{BH}_{3}$. In 2013, Erker and co-workers also reported similar cationic germinal $\mathrm{Zr}^{+} / \mathrm{P}$ Lewis pair (66) and studied its reactivity (scheme 20). ${ }^{31}$ 


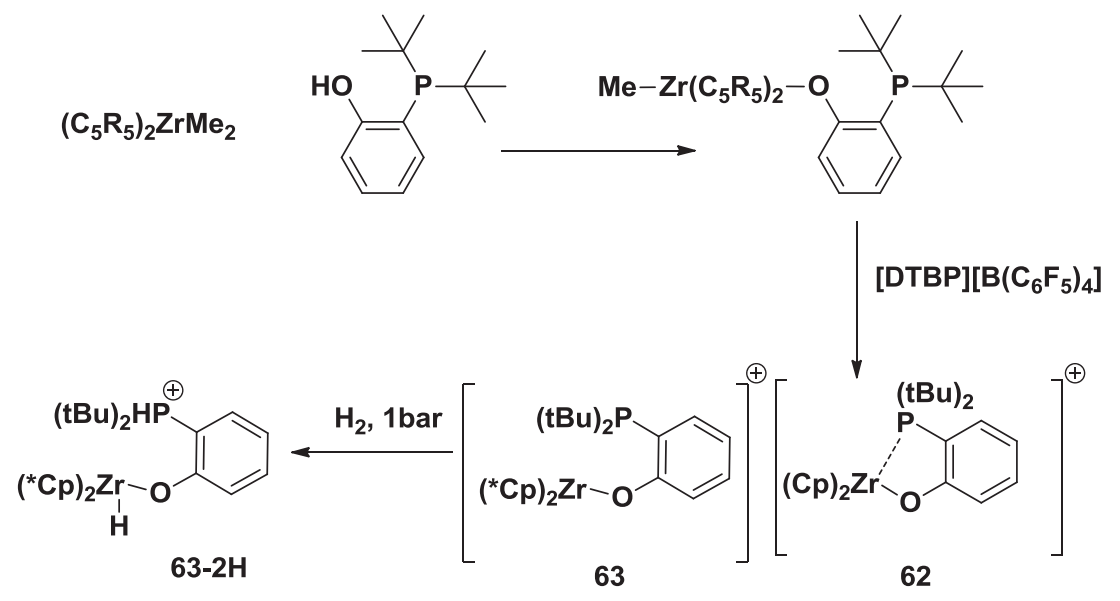

Scheme 19. Zr-Phosphine-based FLP system.

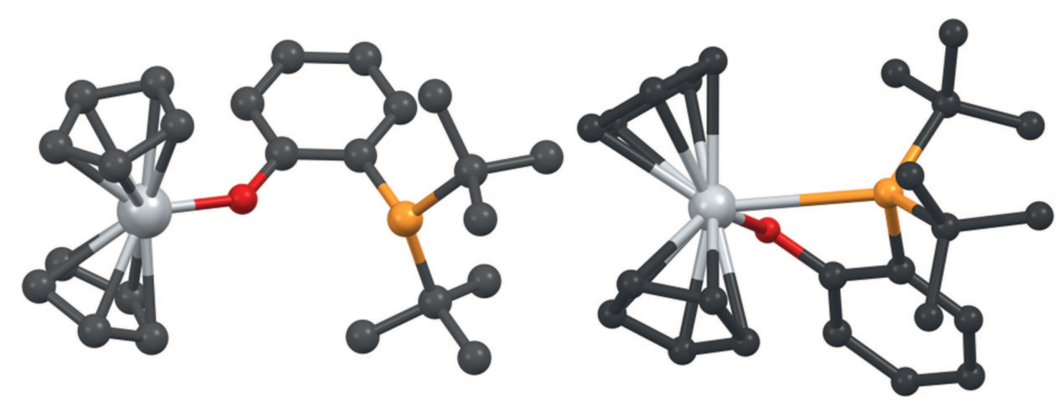

Figure 11. X-ray-obtained molecular structures of 65 and 64. (Colour codes; $\mathrm{C}=$ Black, $\mathrm{Ti}=$ Gray, $\mathrm{P}=$ Orange, $\mathrm{O}=$ Red; hydrogen atoms omitted for clarity).

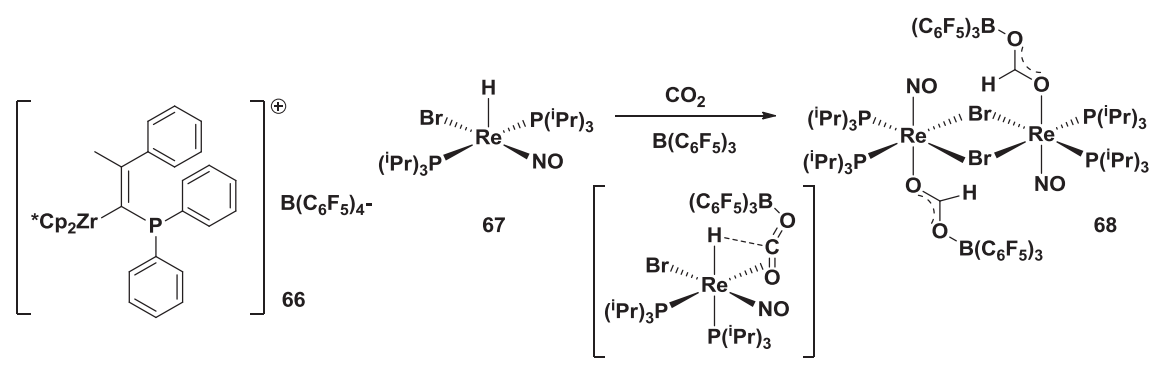

Scheme 20. Dihydrogen activation by a tris[3,5-bis(trifluoromethyl)phenyl] borane $\mathbf{4 3}$ and 2,2,6,6-tetramethylpiperidine-derived FLP system.

Further in 2013, Berke and co-workers illustrated FLP systems with a metal-hydride bond acting as an effective Lewis base component (scheme 20). ${ }^{32}$ In their study, they found that the reaction of $\left[\mathrm{ReHBr}(\mathrm{NO})\left(\mathrm{PR}_{3}\right)_{2}\right](\mathbf{6 7})$ with $\mathrm{B}\left(\mathrm{C}_{6} \mathrm{~F}_{5}\right)_{3}$ under 1 bar of $\mathrm{CO}_{2}$ led to the instantaneous formation of the FLP-type species $\left[\mathrm{ReHBr}(\mathrm{NO})\left(\mathrm{PR}_{3}\right)_{2}\left(\eta^{2}-\mathrm{O}=\mathrm{C}=\mathrm{O}-\mathrm{B}\left(\mathrm{C}_{6} \mathrm{~F}_{5}\right)_{3}\right)\right]$ (68) (figure 12). These FLPs brought about consequent catalytic reduction of $\mathrm{CO}_{2}$ by a hydrosilane and catalytic hydrogenation of $\mathrm{CO}_{2}$ in the presence of sterically hindered strong bases such as 2,2,6,6tetramethylpiperidine.
FLP chemistry has also been exploited in other aspects of transition metal chemistry. Szymczak and co-workers recently used the frustrated Lewis pair as an accessory functionality in the secondary coordination sphere of terpyridine ligand to promote directed Lewis acid/base interactions (scheme 21). ${ }^{33}$ The metal complex 69a, upon addition of $\mathrm{N}_{2} \mathrm{H}_{4} \cdot \mathrm{NEt}_{3}$, forms a $\eta^{1}$ coordinate complex 70a; whereas the FLP-prompted electronic direction in $69 \mathrm{~b}$ resulted in the formation of the first $\eta^{2}-\left[\mathrm{N}_{2} \mathrm{H}_{3}\right]$-vanadium complex 70b (figure 13). The secondary coordination sphere consisting of the borane and amine units enforces the highly directed 


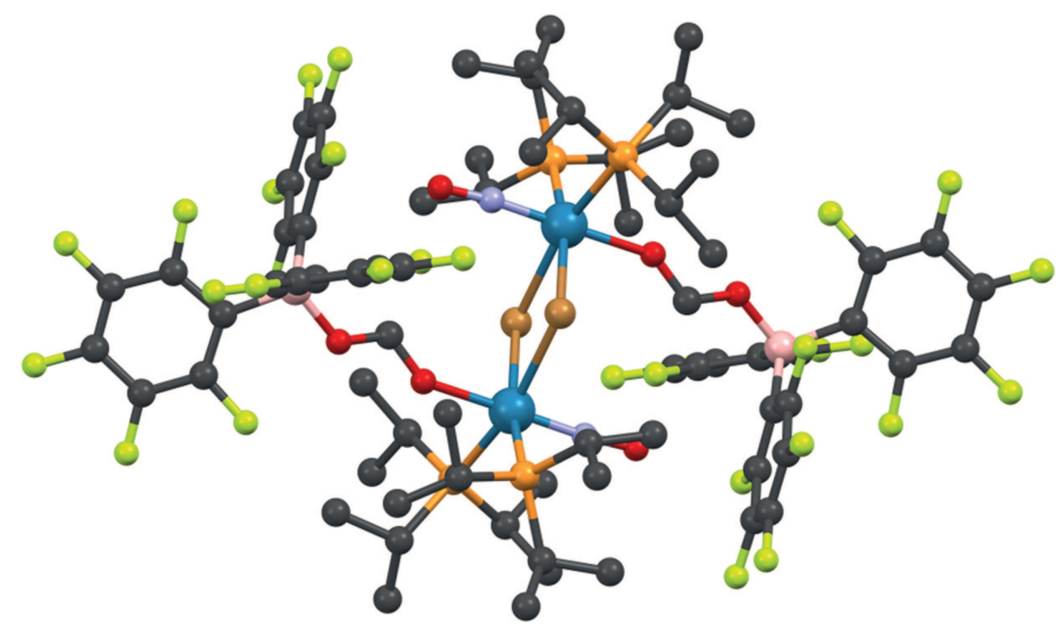

Figure 12. Molecular structures of 68. (Colour codes; $\mathrm{C}=\mathrm{Black}, \mathrm{Re}=$ Greenish-Blue, $\mathrm{P}=$ Orange, $\mathrm{O}=$ Red $\mathrm{B}=$ Pink, $\mathrm{Br}=$ Brown, $\mathrm{F}=$ Green, $\mathrm{N}=$ sky-blue; hydrogen atoms omitted for clarity).<smiles></smiles><smiles></smiles>

Scheme 21. FLP-triggered changes in coordination nature of hydrazine towards V(III).
Lewis acid/base interactions between the metal centre and the incoming ligand.

Stephan and co-workers have also followed similar strategy of FLP-based systems in a Ruthenium tris (aminophosphine) complex (scheme 22). ${ }^{34}$ Compound 71, upon treatment with $\mathrm{KN}\left(\mathrm{SiMe}_{3}\right)_{2}$ in $\mathrm{THF}$ followed by anion metathesis with $\mathrm{NaBPh}_{4}$, resulted in the formation of $\mathbf{7 2}$ in $78 \%$ yield. The structure of $\mathbf{7 2}$ consisted of a pseudo-octahedral $\mathrm{Ru}$, with the amido nitrogen and the adjacent phosphorus atom binding to $\mathrm{Ru}$ affording an NPRu three-membered ring. This strained feature in 72 acts as a driving force for its ready reaction with $\mathrm{CO}_{2}$ resulting in the formation of 73. This binding of $\mathrm{CO}_{2}$ in $\mathbf{7 2}$ is a cooperative action of the pendant Lewis basic phosphine and Lewis acidic Ru centre (figure 13).

\section{Summary and outlook}

The new born chemistry of FLPs has evolved progressively at a fast pace in only last few years and FLPs have already secured their own special place.
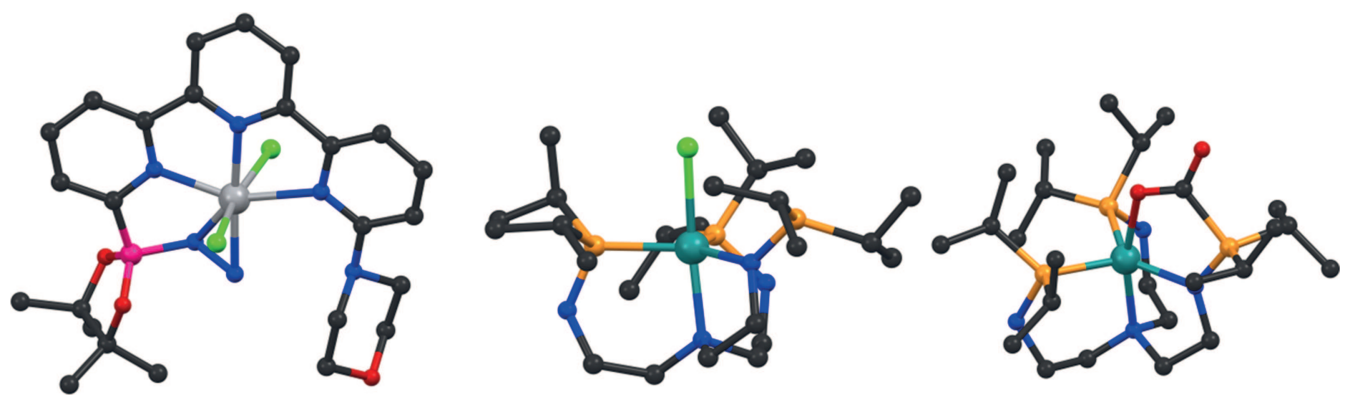

Figure 13. Molecular structures of 70b, 71 and 73. (Colour codes; $C=$ Black, $R u=$ GreenishBlue, $\mathrm{V}=$ Grey, $\mathrm{P}=$ Orange, $\mathrm{O}=$ Red $\mathrm{B}=$ Magenta, $\mathrm{Cl}=$ Green, $\mathrm{N}=$ Blue; hydrogen atoms omitted for clarity). 


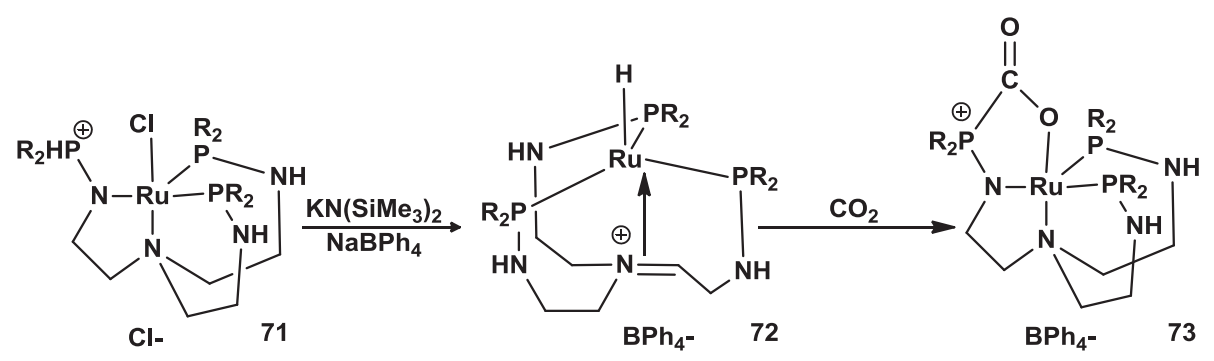

Scheme 22. FLP-inspired Ru-catalyst for activation of carbon dioxide.

FLPs constitute the very first examples of transition metal-free catalysts capable of reversible activation of $\mathrm{H}_{2}$, which have already led to its commercialisation as catalysts for hydrogenation. However, modern synthetic and design principles and strategies have already taken this research out of the corner of main-group chemistry and spread into the fields of transition metal based compounds, increasing its versatility and opportunities. The incorporation of chiral elements in FLP-based catalysts have also allowed the possibilities of asymmetric organic synthesis. Additionally, FLPs have also evolved as potential entities for small molecule activation which can lead to yet other largely unexplored possibilities in the near future. The conceptual simplicity and possible fine-tuning of FLPs are the most important aspects which have encouraged the study of these simple but extremely versatile systems in practical applications. In near future, FLPs are expected to grow as one of the major fields of chemistry and catalysis reaching unexplored areas.

\section{References}

1. Brønsted, J N 1923 Recl. Trav. Chim. Pays-Bas. 42, 718

2. Lewis G N 1923 Valence and the structure of atoms and molecules (New York: Chemical Catalogue Company)

3. Lowry T M 1923 J. Soc. Chem. Ind. 4243

4. (a) Brown H C, Schlesinger H I and Cardon S Z 1942 J. Am. Chem. Soc. 64 325; (b) Brown H C and Kanner B 1966 J. Am. Chem. Soc. 88986

5. Wittig G and Benz E 1959 Chem. Ber. 921999

6. Roesler R, Piers W E and Parvez M 2003 J. Organomet. Chem. 680218

7. Tochtermann W 1966 Angew. Chem. Int. Ed. Engl. 5351

8. Welch G C, Juan R R S, Masuda J D and Stephan D W 2006 Science 3141124

9. (a) Rokob T A, Hamza A, Stirling A, Soós T and Pápai I 2008 Angew. Chem. Int. Ed. 47 2435; (b) Hamza A, Stirling A, Rokob T A and Pápai I 2009 Int. J. Quantum Chem. 109 2416; (c) Bakó I, Stirling A, Bálinta S and Pápai I 2012 Dalton Trans. 419023

10. (a) Grimme $\mathrm{S}$, Kruse H, Goerigk L and Erker G 2010 Angew. Chem., Int. Ed. 49 1402; (b) Schirmer B and Grimme S 2010 Chem. Commun. 46 7942; (c) Rokob T A, Bako I, Stirling A, Hamza A and Papai I J. Am. Chem. Soc. 1354425

11. Welch G C and Stephan D W 2007 J. Am. Chem. Soc. 1291880

12. (a) Spies P, Erker G, Kehr G, Bergander K, Frohlich R, Grimme S and Stephan D W 2007 Chem. Commun. 5072-5074; (b) Spies P, Schwendemann S, Lange S, Kehr G, Fröhlich R and Erker G 2008 Angew. Chem. Int. Ed. 47 7543; (c) Bertini F, Lyaskovskyy V, Timmer B J J, de Kanter F J J, Lutz M, Ehlers A W, Slootweg J C, Lammertsma Koop 2012 J. Am. Chem. Soc. 134 201

13. (a) Jackson R D, James S, Orpen A G and Pringle P G 1993 J. Organomet. Chem. 458 C3-C4; (b) Wang H, Fröhlich R, Kehr G and Erker G 2008 Chem. Commun. 5966

14. Ullrich M, Lough A J and Stephan D W 2009 J. Am. Chem. Soc. 13152

15. Geier S, Gilbert T M and Stephan D W 2008 J. Am. Chem. Soc. 13012632

16. (a) Chen D and Klankermayer J 2008 Chem. Commun. 2130; (b) Chen D, Wang Y and Klankermayer J 2010 Angew. Chem. Int. Ed. 499475

17. (a) Sajid M, Kehr G, Wiegand T, Eckert H, Schwickert C, Pöttgen R, Cardenas A J P, Warren T H, Fröhlich R, Daniliuc C G and Erker G 2013 J. Am. Chem. Soc. 135 8882; (b) Sudhakar P and Thilagar P 2013 J. Chem. Sci. 12541

18. (a) Chase P A, Jurca T and Stephan D W 2008 Chem. Commun. 1701; (b) Sumerin V, Schulz F, Nieger M, Leskela M, Repo T and Rieger B 2008 Angew. Chem. Int. Ed. 47 6001; (c) Sumerin V, Schulz F, Atsumi M, Wang C, Nieger M, Leskela M, Repo T, Pyykko P and Rieger B 2008 J. Am. Chem. Soc. 13014117

19. Geier S J and Stephan D W 2009 J. Am. Chem. Soc. 131 3476

20. Theuergarten E, Schlüns D, Grunenberg J, Daniliuc C G, Jones P G and Tamm M 2010 Chem. Commun. 46 8561

21. Herrington T J, Thom A J W, White A J P and Ashley A E 2012 Dalton Trans. 419019

22. Caputo C B, Zhu K, Vukotic V N, Loeb S J and Stephan D W 2013 Angew. Chem. Int. Ed. 52960

23. Frey G D, Lavallo V, Donnadieu B, Schoeller W W and Bertrand G 2007 Science 316439

24. (a) Chase P A, Stephan D W 2008 Angew. Chem. Int. Ed. 47 7433; (b) Holschumacher D, Bannenberg T, Hrib C G, Jones P G and Tamm M 2008 Angew. Chem. Int. Ed. 477428 
25. Ménard G and Stephan D W 2010 J. Am. Chem. Soc. 1321796

26. (a) Ménard G and Stephan D W 2011 Angew. Chem. Int. Ed. 50 8396; (b) Ménard G and Stephan D W 2012 Angew. Chem. Int. Ed. $\mathbf{5 1} 8272$

27. Ménard G, Hatnean J A, Cowley H J, Lough A J, Rawson J M and Stephan D W 2013 J. Am. Chem. Soc. 1356446

28. Holtrichter-Rößmann $\mathrm{T}$, Isermann $\mathrm{J}$, Rösener $\mathrm{C}$, Cramer B, Daniliuc C-G, Kösters J, Letzel M, Würthwein E-U and Uhl W 2013 Angew. Chem. Int. Ed. $\mathbf{5 2} 7135$
29. Chapman A M, Haddow M F and Wass D F $2011 \mathrm{~J}$. Am. Chem. Soc. 1338826

30. Chapman A M, Haddow M F and Wass D F $2011 \mathrm{~J}$. Am. Chem. Soc. 13318463

31. Xu X, Kehr G, Daniliuc C G and Erker G 2013 J. Am. Chem. Soc. 1356465

32. Jiang Y, Blacque O, Fox T and Berke H 2013 J. Am. Chem. Soc. 1357751

33. Tutusaus O, Ni C and Szymczak N K 2013 J. Am. Chem. Soc. 1353403

34. Sgro M J and Stephan D W 2012 Angew. Chem. Int. Ed. 5111343 